\title{
Michal Kalecki, um pioneiro da teoria econômica do desenvolvimento
}

\author{
JULIO LÓPEZ G. \\ MARTÍN PUCHET A. \\ MICHAEL ASSOUS*
}

Michal Kalecki, a pioneer of development economics. Kalecki made important contributions to development economics, which rank him among the founding fathers of this area of our discipline. The objective of this paper is to give an account of his contributions, and in particular of his conception of the peculiarities and the way of functioning of the underdeveloped economies, and of the barriers that limits their capacity for high and sustained long run growth. As most socialist economists of his time, he was skeptic about the possibilities of overcoming underdevelopment under capitalism. However, in contradistinction to other pioneers of development economics, Kalecki did not stress the international forces that hamper development, but put the accent rather in the internal institutions and social and political determinants. In particular, the feudal and semi-feudal conditions in agriculture, the reduced market ensuing from income concentration and widespread monopolization of the economy, and the lack of willingness of entrepreneurs to carry out the necessary investments. Accordingly, his economic policy recommendations emphasized also the domestic aspects involved.

Keywords: Kalecki; development economics.

JEL Classification: B2; B3; O1.

\footnotetext{
*Respectivamente, Universidad Nacional Autónoma de México, e-mail: gallardo@unam.mx; Universidade Nacional Autónoma de México, e-mail: anyul@unam.mx; Université Paris 1, e-mail: michael. assous@wanadoo.fr. Julio López gostaria de expressar sua profunda gratidão a Ignacy Sachs, que lhe ensinou a maior parte do que ele aprendeu sobre a visão de Kalecki da economia subdesenvolvida. Agradece também o apoio recebido de UNAM-DGAPA-PAPIIT, Proyecto IN301606. Submetido: Outubro 2007; Aprovado: Dezembro 2007.
} 


\section{INTRODUÇÃO}

Kalecki deu importantes contribuições para a teoria econômica do desenvolvimento, que o colocam entre os fundadores dessa área de nossa disciplina. O objetivo deste trabalho é fazer um relato de suas contribuições, em grande parte deixando que o autor fale por si próprio. Começaremos a apresentação de suas ideias resumindo um de seus últimos trabalhos sobre o tema (Kalecki, 1966 [1993]), no qual ele expõe, em seu estilo conciso habitual, sua visão global.

Em primeiro lugar, ele indica que " $\mathrm{O}$ problema crucial da economia subdesenvolvida é diferente do problema dos países desenvolvidos [...] ao contrário das economias desenvolvidas [na primeira os bens de capital], não conseguem absorver toda a mão-de-obra disponível e, em consequência, o padrão de vida é muito baixо...” (Kalecki, 1966 [1993]: 16).

Ele argumenta então: "O problema crucial enfrentado pelos países subdesenvolvidos é, portanto, ampliar consideravelmente os investimentos [...] Há, no entanto, três importantes obstáculos ao aumento dos investimentos. Primeiro, é possível que o investimento privado não esteja disponível em ritmo adequado. Em segundo lugar, podem faltar recursos físicos para produzir mais bens de investimento. Em terceiro lugar, mesmo se essas duas dificuldades forem superadas, existe ainda o problema da oferta adequada de produtos de primeira necessidade para suprir a demanda resultante do aumento do emprego" (Ibid.: 16).

$\mathrm{O}$ autor reconhece então que esses obstáculos poderiam ser superados com medidas apropriadas. Ele se refere à "intervenção do governo na esfera do investimento com o objetivo de garantir o volume e estrutura planejados, a superação das barreiras institucionais ao rápido desenvolvimento da agricultura e a taxação adequada dos indivíduos ricos e prósperos" (Kalecki 1966 [1993]: 19). Mas ele conclui suas reflexões com este diagnóstico bastante sombrio: “[Esses] três problemas [...] apresentam claramente um gigantesco problema político [...] A superação de todos os obstáculos ao desenvolvimento econômico enumerados acima significa mais do que a convulsão causada no século XVIII pela Revolução Francesa. Assim, não surpreende que essas reformas não sejam realizadas pacificamente. Um desenvolvimento vigoroso mas equilibrado [...] dificilmente se encontra na prática. $\mathrm{Na}$ verdade encontramos dois tipos de desenvolvimento (talvez com alguns casos intermediários): ou o desenvolvimento é não inflacionário, mas extremamente lento, ou é relativamente rápido e acompanhado de violentas pressões inflacionárias” (Ibid.).

Discutiremos agora em mais detalhes a análise econômica teórica de Kalecki sobre as economias subdesenvolvidas. Posteriormente, vamos tentar conceber uma estratégia econômica para estimular a recuperação econômica e promover o crescimento elevado e equilibrado a longo prazo, com base em sua visão global. 


\section{A MACROECONOMIA DAS ECONOMIAS SUBDESENVOLVIDAS DE KALECKI}

A primeira contribuição escrita de Kalecki ao estudo dos países subdesenvolvidos foi feita em sua análise de Manoilescu (1931). ${ }^{1}$ Como o leitor poderá se lembrar, o economista e político romeno Manoilescu era um veemente partidário do protecionismo e da industrialização nos países subdesenvolvidos, e um crítico da teoria ortodoxa do comércio internacional baseada nas vantagens comparativas e na teoria do valor do trabalho. ${ }^{2}$ Sua defesa do protecionismo foi severamente condenada pelos economistas convencionais, mas Kalecki apoiou a defesa de Manoilescu.

Ele afirmou que "é o autor [isto é, Manoilescu] que está certo em sua solução do problema da proteção nos países agrícolas” (Kalecki, 1938 [1993]: 181). Kalecki argumentou que "é [...] realista presumir que em um país agrícola exista algum desemprego, manifesto ou disfarçado, e portanto a oferta de poupança nova não está fixada de modo algum: ela é igual ao investimento realizado [...]. Se alguma indústria nova for protegida, a oportunidade de investimento aumenta e a oferta de capital aumenta pro tanto" (Ibid.). Em outras palavras, Kalecki acreditava que novas indústrias seriam convenientes do ponto de vista do país porque, em uma situação de desemprego generalizado, o custo da mão-de-obra para a economia seria muito baixo, e porque os investimentos adicionais trariam consigo sua própria oferta de poupança. Em um estudo posterior ele seria mais explícito, mencionando que "Em países subdesenvolvidos, a força de trabalho adicional geralmente virá das zonas rurais. Em muitos casos, a produção agrícola não cairá, como resultado da 'mão-de-obra excedente', na agricultura” (Kalecki, 1954 [1993]: 28).

No entanto, Kalecki concluiu a análise de Manoilescu com sua própria crítica: "A tendência do autor de apresentar a proteção como a solução para o problema da industrialização dos países agrícolas é definitivamente enganosa [...] Apresentar o livre comércio como o único obstáculo ao progresso econômico dos países atrasados é desviar a atenção para urgentes problemas sociais como a reforma agrária e outros" (Kalecki 1938 [1993]: 182; ênfase no original).

Kalecki continuou suas reflexões sobre a economia dos países subdesenvolvidos durante seu trabalho no Departamento Econômico da Secretaria-Geral da ONU. ${ }^{3}$ Parte de suas opiniões muito provavelmente apareceu em documentos ofi-

\footnotetext{
${ }^{1}$ Antes de deixar a Polônia em 1936, Kalecki não estudou as características específicas de uma economia subdesenvolvida em seus escritos relativos ao seu país natal, que na época era claramente subdesenvolvido.

${ }^{2}$ Manoilescu (1929) foi originalmente publicado nessa data em sua Romênia natal e republicado em português no Brasil em 1931, com um prefácio especial do autor.

${ }^{3}$ Nas obras de Kalecki do início dos anos 1940 não encontramos nenhum outro estudo relativo às economias subdesenvolvidas. No entanto, supomos que ele tenha trocado ideias sobre o tema com Josef Steindl, seu mais próximo colaborador no Instituto de Economia e Estatística de Oxford, à época
} 
ciais desse organismo. ${ }^{4}$ No entanto, ele expressou suas opiniões mais pessoais em resposta a convites para trabalhar como consultor ou como palestrante convidado em países em desenvolvimento.

Provavelmente o melhor ponto de partida para uma exposição detalhada e analítica de suas ideias é seu trabalho sobre "The problem of financing economic development" [O problema de financiar o desenvolvimento econômico], resultado de uma palestra dada por ele em 1953 no "Centro de Estudios Monetarios Latinoamericanos”, na Cidade do México (Kalecki, 1954 [1993]). Nesse trabalho, o objetivo era estudar o problema do financiamento do desenvolvimento econômico, mas sua análise é também uma investigação sobre os fatores que limitam a acumulação de capital e o crescimento de longo prazo nas economias subdesenvolvidas. Selecionaremos alguns parágrafos desse trabalho que refletem sua abordagem global e em seguida faremos algumas observações gerais sobre as ideias de Kalecki.

Inicialmente, o autor especifica as características institucionais e estruturais da economia subdesenvolvida. Ele distinguia três classes sociais principais: "capitalistas, trabalhadores e pequenos proprietários. O último grupo inclui camponeses pobres, artesãos, pequenos comerciantes etc." (Kalecki, 1954 [1993]: 23). Ele também " $[\ldots]$ subdivide a economia em dois setores, que produzem bens de capital e bens de consumo, respectivamente [Departamentos I e II, respectivamente; JL, MP e MA]. Em cada setor [ele] inclui a produção das respectivas commodities a partir do estágio mais baixo" (Ibid.). O Departamento II é posteriormente dividido em bens de consumo agrícolas e não-agrícolas.

em que Steindl estava escrevendo seu relato "The impact of war on India" [O impacto da guerra na Índia]". Reproduzimos aqui algumas partes relevantes do trabalho de Steindl: "Ao contrário de outros países envolvidos na guerra, a Índia tem uma abundante oferta de mão-de-obra. Ela assume a forma de um 'desemprego disfarçado', [...], pois uma parte considerável da população atual é totalmente excedente, de tal forma que retirá-la da agricultura não envolveria nenhuma redução na produção final. [...]. Um aumento considerável na produção de guerra (o que, de fato, representaria uma industrialização parcial), [e][...] uma transferência substancial de mão-de-obra do 'desemprego disfarçado' para o emprego industrial aumentará portanto a demanda por bens de consumo, entre outras coisas, e também a demanda por alimentos.[...] [No entanto] Parece que uma característica da produção agrícola da Índia é ser bastante inelástica [...] Em vista da inelasticidade da produção agrícola, a expansão do poder aquisitivo na Índia deve ter, em grande parte, o efeito de aumentar preços" (Steindl, 1942 [1946]:129-131).

${ }^{4}$ Dell (1977) fornece um fascinante relato das atividades e influência de Kalecki no Departamento Econômico da Secretaria Geral da ONU, e destaca alguns dos materiais oficiais nos quais as opiniões podem ser atribuídas a Kalecki. Assim, podemos encontrar uma afirmação muito típica de Kalecki: "Qualquer estimativa da marcha dos acontecimentos na Índia e na América Latina num futuro próximo deve levar em conta os esquemas de desenvolvimento em grande escala em que esses países provavelmente embarcarão [...] Se a taxação direta não for aumentada, a inflação virá, assim como ocorreu durante a guerra. No entanto, mesmo se os gastos com o desenvolvimento forem compensados pela taxação direta, o problema da inflação nos preços dos alimentos não será solucionado, porque a taxação das rendas mais elevadas dificilmente reduzirá a demanda por alimentos. A longo prazo, o aumento na produção de alimentos constituirá sem dúvida uma parte muito importante do programa de desenvolvimento dos países subdesenvolvidos. Isso exigirá mudanças sociais e técnicas fundamentais nas economias agrícolas” (Dell, 1977: 40). 
Kalecki a seguir critica a opinião segundo a qual é "a falta de mercados adequados [que é] o principal obstáculo ao desenvolvimento, mais do que a inflação. O problema costumava ser formulado da seguinte forma. Em vista da pequena demanda interna, não haverá escoamento para os produtos das fábricas recentemente construídas. Assim, a industrialização se mostrará impossível, a menos que esteja orientada para os mercados externos. A resposta a esse problema é: “[...] se o investimento for suficientemente alto, ele impulsionará a demanda por bens de consumo até o ponto em que o excedente desses bens no Departamento II encontre a maior demanda de trabalhadores e capitalistas no Departamento I. Desse modo, é o próprio alto nível de investimento que gera demanda por bens de consumo" (Kalecki, 1954 [1993]: 29). Como o leitor poderá notar, a visão de Kalecki, claramente baseada no princípio da demanda efetiva, é afirmada em termos muito mais precisos do que nos escritos de outros fundadores da teoria econômica do desenvolvimento, como p.ex. Rosenstein-Rodan (1943) e Nurkse (1943).

Kalecki também observa que "O investimento pode ser limitado [...] pela reticência dos empresários em expandir seus gastos com bens de capital. Nessa situação, o investimento público adquire uma importância crucial para o processo de rápido desenvolvimento econômico [...]" (Kalecki, 1954 [1993]: 27). Ele prossegue a análise, identificando as pressões inflacionárias como o principal obstáculo que surge nos países subdesenvolvidos quando se acelera o investimento. $\mathrm{Na}$ verdade, “em alguns setores do Departamento II a oferta de bens de consumo pode ser elástica e em outros, rígida. Um exemplo importante dessa situação em países subdesenvolvidos é o caso em que a oferta de bens de consumo industriais é elástica porque há reservas consideráveis de capacidade produtiva ou porque o aumento dessa capacidade pode não exigir um investimento muito grande. Por outro lado, a oferta de alimentos pode ser razoavelmente rígida. Isso dependerá do fato de que, nas condições predominantes nos países subdesenvolvidos, a produção de alimentos em resposta à demanda se expande em ritmo inferior ao dos países desenvolvidos" (Ibid.: 28). Ele desenvolveu depois esse ponto de vista argumentando que: "O importante é que, em uma economia subdesenvolvida, a produção agrícola é afetada por um grande número de limitações, que a impediriam de crescer a taxas elevadas mesmo se todos os recursos materiais estivessem disponíveis. Esses poderosos obstáculos ao desenvolvimento da agricultura são as relações feudais ou semifeudais na ocupação da terra e a dominação dos camponeses pobres pelos comerciantes e agiotas. Assim, é impossível haver uma aceleração radical do desenvolvimento da agricultura sem a introdução de mudanças institucionais substanciais” (Kalecki, 1966 [1993:18).5

\footnotetext{
${ }^{5}$ Aproveitaremos esta oportunidade para uma reminiscência pessoal. Um dos autores do presente trabalho (JL) abordou Kalecki com uma pergunta relativa a um assunto que esteve muito em voga na América Latina no final dos anos 1960. "O senhor acha que em países subdesenvolvidos as condições agrárias são realmente semifeudais, ou não seriam elas simplesmente capitalistas?” A resposta, no seu estilo lacônico habitual, foi: "O senhor acha que isso é realmente importante?".
} 
Kalecki então afirma: "Pode-se demonstrar que, em alguns casos, a rigidez da oferta de alimentos pode levar à subutilização dos bens de consumo não-alimentares. Isso não acontecerá se os camponeses puderem tirar proveito dos aumentos nos preços dos alimentos pois, com uma renda mais elevada, eles comprarão mais produtos manufaturados. No entanto, se os benefícios do aumento nos preços dos alimentos reverterem para os proprietários, comerciantes ou agiotas, então a redução nos salários reais ocasionada pelo aumento nos preços dos alimentos não terá, como contrapartida, um aumento da demanda por bens de consumo de massa por parte do campo, pois esse aumento do lucro não será gasto de modo algum, ou será gasto em supérfluos" (Kalecki, 1954 [1993]: 29).

Kalecki a seguir discute os efeitos do aumento da produção agrícola e do crescimento da produtividade do trabalho. "Enquanto a oferta adequada de alimentos é de importância fundamental na prevenção da inflação [...] os aumentos da produtividade industrial trabalham na mesma direção. Há, no entanto, uma importante diferença. Um aumento na oferta de alimentos tende a elevar os salários reais em um determinado nível de emprego não-agrícola. Por outro lado, um aumento da produtividade tende a aumentar os salários reais através de uma redução do nível de emprego correspondente a um determinado nível de produção não-agrícola." (Ibid.: 30). Além disso, "se houver um aumento no grau de monopólio que cause uma mudança nos lucros [...] a elevação dos preços em relação aos salários reduzirá a demanda efetiva e impedirá a plena utilização das instalações produtivas [...] O resultado final será uma mudança na distribuição de renda: dos salários e das rendas agrícolas para os lucros industriais" (Ibid.: 32).

A conclusão de Kalecki pode ser esclarecida com a ajuda das seguintes equações, que sintetizam sua teoria. ${ }^{6}$ Digamos que P simbolize os lucros, I o investimento privado, $C^{k}$ o consumo capitalista, $X$ as exportações, $M$ as importações, $\beta$ o déficit orçamentário e Y o produto final total. Por outro lado, $\omega$ é a parcela relativa dos salários no valor agregado (ou produto final); $\varepsilon$ é a parcela dos lucros no produto final ( $\varepsilon=1-\omega$, numa hipótese simplificadora); $k$ é o "grau de monopólio", ou a relação entre o total dos rendimentos e os total dos custos diretos, que também é igual à relação entre os preços médios e os custos diretos médios; e $j$ é a relação entre o custo total das matérias-primas e a folha de salários.

$$
\begin{aligned}
& P=I+C^{K}+(X-M)+\beta \\
& \omega=\frac{1}{1+(k-1)(j+1)}, k>1 \\
& \varepsilon=1-\omega=\frac{(K-1)(j+1)}{1+(k-1)(j+1)} \\
& Y=\frac{P}{\varepsilon}=\frac{I+C^{k}+(X-M)+\beta}{\varepsilon}
\end{aligned}
$$

\footnotetext{
${ }^{6}$ Sugerimos também ao leitor interessado a excelente formalização e ampliação das principais ideias de Kalecki feita por Fitzgerald (1990: 183-203).
} 
A equação (1) é a conhecida equação de Kalecki para os lucros totais em uma economia aberta (na qual fazemos abstração da poupança dos trabalhadores por razões de simplificação). ${ }^{7}$ A equação (2) mostra que (para uma determinada composição de produto final) a parcela relativa dos salários no valor agregado é determinada pelo grau de monopólio e pela relação entre o custo das matérias-primas e a folha de salários. A equação (3) é a teoria de Kalecki sobre a parcela relativa dos lucros na renda nacional. A equação (4) faz com que o produto final total dependa dos lucros totais e da parcela dos lucros no produto final.

Agora, vamos usar o modelo para discutir as ideias anteriores de Kalecki. Uma maior parcela de lucros - ocasionada seja pela queda nos salários urbanos seja pelo aumento do grau de monopólio - não se traduzirá necessariamente em maiores lucros totais. Estes últimos não aumentarão quando os salários caem, a menos que o consumo ou o investimento capitalistas cresçam simultaneamente. Por outro lado, a demanda efetiva é reduzida quando ocorre uma mudança dos salários para os lucros. Em outras palavras, a distribuição da renda é um determinante essencial da demanda efetiva, e quando ela se altera contra os trabalhadores a demanda é afetada negativamente.

A novidade da abordagem e das conclusões de Kalecki pode ser evidenciada se as compararmos com o trabalho clássico de A. W. Lewis (1954). Como o leitor poderá recordar, Lewis propôs um modelo de economia dual, no qual um setor moderno (industrial) coexiste com um setor atrasado (agrícola). A produtividade marginal do trabalho industrial é descrescente, mas é superior à produtividade da agricultura. Os salários industriais reais dependem, e estão fixados, em um nível superior ao da subsistência dos trabalhadores agrícolas. Nesse nível, as empresas industriais podem empregar tantas pessoas quantas desejarem e contratarão trabalhadores até o ponto em que o salário real destes seja igual à produtividade industrial. Salários reais mais baixos acarretam maiores lucros industriais e todos os lucros são automaticamente reinvestidos. Assim, quanto maior for a diferença excedente entre a produtividade industrial média e os salários industriais reais médios, maiores serão o nível e a taxa de investimento, maior a taxa de crescimento industrial e mais rápida a absorção do excedente de mão-de-obra agrícola. Na verdade, Lewis chega mesmo a argumentar que uma queda no padrão de vida da população pobre do campo terá efeito positivo sobre os lucros industriais, pois reduzirá os salários urbanos. Maiores lucros estimularão os investimentos, que tenderão a aumentar a taxa de crescimento econômico.

Kalecki, por seu lado, negava explicitamente que uma maior parcela de lucros necessariamente aumentasse a taxa de crescimento do investimento e do produto final e acarretasse uma absorção mais rápida do excedente de mão-de-obra. Há muitas razões para isso. Uma é que, mesmo se obtiverem lucros elevados, as em-

\footnotetext{
${ }^{7} \mathrm{Na}$ equação completa dos lucros formulada por Kalecki, a poupança dos trabalhadores reduz os lucros, porque deprime a demanda efetiva sem reduzir os custos diretos.
} 
presas podem relutar em investir. A outra está relacionada ao efeito das maiores parcelas de lucros sobre a demanda agregada, os lucros totais e o produto final; pois, segundo ele, os lucros totais não aumentam necessariamente com uma maior parcela de lucros. Esse aspecto é totalmente negligenciado por Lewis, que assume que maiores parcelas de lucros serão acompanhadas de maiores lucros absolutos, maior taxa de lucro e maior taxa de acumulação.

Por outro lado, Kalecki também considerava que um aumento no padrão de vida dos camponeses pobres teria influência benéfica sobre a demanda efetiva e o emprego, sob dois aspectos. Por um lado, ampliaria o mercado agrícola para os bens de consumo industriais. Além disso, estimularia um aumento dos salários reais, o que ampliaria a demanda por bens de consumo nas áreas urbanas.

Da mesma forma, somente quando preços agrícolas mais elevados beneficiam os camponeses pobres é que a demanda agregada e o produto final serão aumentados. Se o aumento dos lucros rurais resultante dos preços agrícolas mais elevados for apropriado somente pelos proprietários, comerciantes e agiotas, ele não acarretará aumento do consumo e do investimento. Incidentalmente, essa é uma - mas apenas uma - das razões econômicas pelas quais Kalecki defendia fortemente a reforma agrária.

No trabalho que estamos discutindo, Kalecki (1954 [1993]) levantou vários outros pontos, que não foram retomados ou que foram considerados de maneira diferente pelos pioneiros da teoria econômica do desenvolvimento. Vamos nos referir agora a três questões: i) a presença e a importância econômica da capacidade ociosa nos países subdesenvolvidos, ii) os efeitos da maior produtividade do trabalho sobre o crescimento econômico; e iii) o problema da inflação.

Quando Kalecki formulou o princípio da demanda efetiva, ele implicitamente rejeitou o critério de eficiência, oculto em uma concepção que vê o desemprego em massa de pessoas e máquinas como consequência da falta de valor econômico dos recursos não utilizados. ${ }^{8}$ Ao contrário, ele considerava que recursos ociosos constituem um desperdício, resultante de uma falha sistêmica. Encontramos a mesma ideia em sua análise das economias subdesenvolvidas; e ele foi um dos poucos, entre os pioneiros da teoria econômica do desenvolvimento, a enfatizar o desperdício que os bens de capital ociosos implicam, em geral e em particular, para as economias pobres em capital. ${ }^{9}$ Além disso, quando o desemprego de mão-de-obra se alia à utilização

\footnotetext{
${ }^{8}$ Keynes também rejeitou implicitamente esse ponto de vista ortodoxo. Relembrando o período em que predominava o pensamento econômico keynesiano, os economistas neoclássicos não apenas concordavam com essa conclusão, mas a levaram adiante, no que se tornou uma produtiva fertilização cruzada de ideias. Na verdade, aceitava-se que, na presença de distorções internas, uma economia de mercado descentralizada não atingiria seu ótimo de Pareto e os recursos, portanto, poderiam acabar ficando ociosos; isso acarretaria um desperdício, do ponto de vista da economia como um todo. Com o declínio da importância do pensamento econômico keynesiano, essas ideias desapareceram do pensamento econômico neoclássico.
}

${ }^{9}$ Prebisch (1951) também enfatizou essa característica das economias em desenvolvimento. 
da capacidade ociosa, ele destacava a possibilidade de utilizar esses recursos para acelerar o crescimento econômico sem custo ou a baixo custo. Desse modo, do ponto de vista do interesse da economia como um todo, ele acreditava ser melhor colocar os recursos ociosos em uso do que mantê-los sem utilização.

Por outro lado, Kalecki não achava que, em situações de desemprego, a maior produtividade fosse por si só uma panaceia. Quando um aumento da produtividade do trabalho é acompanhado por um aumento simultâneo e proporcional dos salários, o grau de monopólio (k) não varia, mas o custo agregado das matériasprimas em relação à folha de salários (j) aumenta (ver equações 2 e 3 acima). Se o consumo e o investimento capitalistas não aumentarem, então a demanda agregada e o produto final cairão (ver equação 4), o que ocasionará menor nível de emprego, porque o produto final caiu e a produtividade aumentou. Além disso, se os menores custos unitários de mão-de-obra resultantes da maior produtividade do trabalho não forem transferidos para os consumidores por meio de reduções proporcionais de preço, ou se não forem acompanhados por um aumento proporcional dos salários, o grau de monopólio aumentará. Então, para um dado nível de consumo e investimento capitalistas, a demanda efetiva e o produto final serão muito menores; e a redução do emprego será maior ${ }^{10}$.

Finalmente, pode-se também creditar a Kalecki a proposta de uma nova teoria da inflação nas economias em desenvolvimento, segundo a qual a inflação acontece porque a produção de alimentos tem uma oferta inelástica em relação aos preços. Observe-se que a inelasticidade da oferta é um fenômeno tanto de curto como de longo prazo. Ela decorre da configuração institucional desse setor e do limitado papel do aumento de preços e do aumento da produtividade relativa sobre a oferta. Além disso, a inflação aparece antes que a indústria alcance um estágio de plena utilização da capacidade e não contribui para aumentar essa utilização; ela pode mesmo reduzir a demanda e a utilização efetivas. Observe-se também que as ideias de Kalecki sobre o assunto foram retomadas por economistas latino-americanos, que formularam uma teoria estruturalista da inflação durante os anos 1950 e 1960 (Noyola, 1956; Sunkel, 1960; Furtado, 1960).

\section{O REGIME ECONÔMICO INTERMEDIÁRIO}

A contribuição de Kalecki para a teoria do subdesenvolvimento não se limitou a assuntos econômicos. $\mathrm{Na}$ estrutura das economias subdesenvolvidas ele identifi-

\footnotetext{
${ }^{10}$ A conclusão de Kalecki precisa ser corrigida quando levamos em conta uma economia aberta. Pois, nessa situação, a queda nos custos unitários de mão-de-obra aumenta a competitividade, e as exportações e a balança comercial poderão melhorar, ocasionando um aumento dos lucros e da demanda agregada. Assim, o emprego também poderá aumentar. Mas esse ponto também não foi levado em conta, na época, por outros economistas do desenvolvimento, possivelmente porque as exportações industriais das economias em desenvolvimento não eram consideradas viáveis, de qualquer modo.
} 
cou um tipo de Estado, surgido da emancipação política, no qual o poder é assumido por representantes da classe média. A característica-chave desse tipo de Estado é o fato de ele ser constituído como um "regime intermediário" entre as economias capitalistas desenvolvidas e as economias socialistas com planejamento central. ${ }^{11}$ Esses regimes surgiram depois da Segunda Guerra Mundial como consequência da luta contra o colonialismo e outras formas imperialistas de dominação, num período em que, tanto nos países capitalistas desenvolvidos quanto nos países socialistas, a intervenção do Estado e o planejamento econômico haviam se tornado generalizados.

Nessas circunstâncias internacionais, de surgimento de novas nações independentes e de governos anti-imperialistas, e de forte intervenção do Estado, Kalecki postulava que governos liderados por representantes da classe média baixa teriam de preencher algumas condições para sua permanência. "Para se manterem no poder eles precisam: i) Alcançar a emancipação não apenas política mas também econômica, isto é, obter um certo grau de independência do capital estrangeiro. ii) Fazer a reforma agrária. iii) Garantir o contínuo crescimento econômico; este último ponto está intimamente relacionado aos outros dois” (Kalecki, 1993 [1964]: 6-7).

Esse tipo de análise, associando, de um lado, o eleitorado social do poder político e o regime correspondente com, de outro lado, o caminho do desenvolvimento econômico, é uma característica predominante do pensamento de Kalecki. Como alguns economistas latino-americanos, ele postulava que os caminhos econômicos pelos quais os países optam e suas características particulares - em termos dos perfis de investimento e distribuição da renda - não são sobredeterminados pelas estruturas econômicas. Ao contrário, eles dependem das correlações entre grupos, setores e classes sociais no poder, da inserção dos governos na área internacional e dos regimes que as elites conseguem estabelecer.

O padrão ou tipo de desenvolvimento que as economias buscam depende, em grande parte, de como os processos sociais e políticos estão interligados com os processos estritamente econômicos. Kalecki salienta que regimes intermediários poderiam prosperar em seus esforços para alcançar o desenvolvimento através da intervenção do Estado, pela existência de circunstâncias como as mencionadas a seguir. A classe média baixa não ficará sujeita à vontade e aos interesses das grandes corporações, enquanto os segmentos superiores da mesma classe são fracos e incapazes de assumir o papel dos "empresários dinâmicos". Ao mesmo tempo, a competição entre países socialistas e países capitalistas desenvolvidos para influenciar os regimes intermediários deu origem a possibilidades de créditos externos com menores graus de condicionamento interno político e econômico (Kalecki, 1993 [1964]: 8). Tais circunstâncias ampliaram a possibilidade de um capitalismo baseado em empresas e

\footnotetext{
${ }^{11}$ J. Osiatinski, o editor das Obras Completas de Kalecki, sugere que, na elaboração da teoria dos "regimes intermediários", Kalecki recebeu inspiração de I. Sachs, seu estreito colaborador no Centro do Pesquisas sobre Economias Subdesenvolvidas, em Varsóvia. Ver Kalecki, 1993, esp. pp. 199-204.
} 
organizações públicas, em políticas orientadas para o investimento, na criação e utilização da capacidade produtiva, bem como na redistribuição de renda.

Exemplos de regimes intermediários típicos eram a Índia e o Egito, aos quais Kalecki acrescentou a Bolívia. Este último era anômalo, em razão da elevada participação de mineiros no governo nascido da revolução de 1952 (Kalecki e Kula, em Kalecki, 1993 [1970]: 169-173). As mudanças na correlação interna das forças sociais no poder, juntamente com suas alianças internacionais - algumas delas não alinhadas com nenhum bloco e outras alinhadas com um dos grandes blocos - levou os regimes intermediários a diferentes caminhos de política econômica.

Para concluir este ponto, existem pelo menos duas importantes lições que podemos tirar para os países latino-americanos, em termos da concepção de uma estratégia socioeconômica progressista.

No caso de governos que representam os interesses dos "empresários dinâmicos", das classes médias, dos trabalhadores e de outros importantes grupos da população, o espaço de manobra para a intervenção do Estado é função das possibilidades de acordos e alianças internacionais referentes à mobilidade do capital estrangeiro. Essa é a primeira lição quando se buscam condições favoráveis para um padrão de investimento capaz de assegurar crescimento econômico sustentado.

Por outro lado, governos que representam coalizões de grupos sociais, formadas para dar suporte a políticas econômicas que favorecem o desenvolvimento e a progressiva redistribuição de renda, precisam reconhecer os limites oriundos da falta de competição política entre os blocos econômicos internacionais. A segunda lição de Kalecki pode, assim, ser formulada do seguinte modo: sempre que houver concepções diferentes entre os blocos econômicos internacionais dominantes sobre o que deve ser feito para promover o crescimento em países subdesenvolvidos, ampliam-se as possibilidades de tomar medidas afirmativas e eficazes. A Coreia poderia ser um bom exemplo de como as concepções divergentes acerca do desenvolvimento econômico nos anos 1970, entre os EUA de um lado e o Japão de outro, ajudaram a aumentar o poder de barganha para a intervenção do Estado.

\section{ESTRATÉGIA DE DESENVOLVIMENTO}

Estudaremos agora como Kalecki imaginava uma estratégia de crescimento para uma economia em desenvolvimento. É um exercício mais ou menos especulativo, pois o autor nunca formulou uma proposta específica. Apesar disso, quando discutiu os problemas das economias em desenvolvimento, e mais ainda quando atuou como consultor convidado, ele forneceu muitas pistas de como imaginava uma estratégia econômica. Além disso, suas reflexões sobre as economias capitalistas avançadas e sobre as economias socialistas fornecem ideias sobre essa mesma questão. Daremos ênfase a uma economia subdesenvolvida semi-industrializada porque isso nos permitirá combinar três linhas teóricas desenvolvidas pelo autor. 
$\mathrm{Na}$ verdade, como afirma I. Sachs, "A posição única de Kalecki no pensamento econômico contemporâneo repousa em suas contribuições pioneiras a cada uma das três principais áreas da economia política: a dinâmica do capitalismo monopolista, o crescimento sob o socialismo e a teoria e prática do planejamento do desenvolvimento em economias mistas" (Sachs, 1977: 47).

Vamos destacar o estudo feito por nosso autor para a economia israelense (Kalecki 1993 [1951]), que consideramos de grande importância por duas razões. Primeiro, porque é o único trabalho em que Kalecki analisa explicitamente o caso do que atualmente chamamos de uma economia semi-industrializada. Em segundo lugar, porque aqui ele formula uma série de propostas de estratégia e política econômica para uma economia capitalista com intervenção do Estado.

\section{A) Observações gerais}

Inicialmente, devemos dizer que as economias semi-industrializadas ocupam um lugar intermediário entre as economias de capitalismo avançado e as economias realmente subdesenvolvidas, que são aquelas às quais Kalecki deu mais atenção em seus trabalhos teóricos e aplicados; e compartilham algumas das características de ambas. Destacaremos duas de suas características que mais se assemelham às das economias subdesenvolvidas. Em primeiro lugar, não é possível eliminar o desemprego a curto e médio prazos, mesmo quando elas utilizam plenamente seus bens de capital.

Em segundo lugar, nessas economias a elasticidade-renda da demanda por alimentos é alta, enquanto a elasticidade da oferta agrícola é baixa, em razão principalmente de fatores técnicos e institucionais. Consequentemente, quando a renda per capita cresce, tendem a surgir fortes pressões inflacionárias ou déficits externos, ou ambos. Mais de quatro décadas se passaram desde que Kalecki destacou essa situação, mas, infelizmente, em muitas economias subdesenvolvidas, e mesmo em economias semi-industrializadas, os obstáculos institucionais à produção agrícola ainda estão presentes.

Apesar disso, as economias semi-industrializadas também se assemelham às economias plenamente desenvolvidas porque, embora os bens de capital não sejam muitos, geralmente uma parte importante deles não é utilizada, especialmente no setor manufatureiro. Em seu trabalho sobre a economia israelense, Kalecki observou: "Deve-se salientar, porém, com relação à escassez de equipamentos, que em alguns ramos da indústria existe considerável capacidade ociosa. A situação nesses casos é mais ou menos a que segue. O consumo interno dos bens manufaturados nesses estabelecimentos não plenamente utilizados não pode ser aumentado, porque isso envolveria maiores importações, enquanto que as exportações desses bens ainda não se desenvolveram [...]" (Kalecki, 1951 [1993]: 98). ${ }^{12}$ Nesse sentido, essas economias

\footnotetext{
${ }^{12}$ A ideia de que a falta de uma capacidade de importação suficiente impede uma maior utilização dos estabelecimentos produtivos é baseada na noção de que "a moeda estrangeira [...] é o fator mais es-
} 
são diferentes das tipicamente subdesenvolvidas pelo fato de que, nestas últimas, apesar de haver capacidade ociosa, sua importância é menor. A capacidade ociosa é uma característica importante e constitui uma premissa fundamental sobre a qual pode ser baseada uma proposta de curto prazo, inspirada na teoria de Kalecki.

Bem, Kalecki acreditava que três condições devem ser preenchidas para que as economias mistas consigam alcançar uma taxa elevada e sustentada de crescimento da produção: i) controle do comércio exterior e do financiamento externo, ii) controle dos investimentos privados a fim de evitar projetos indesejáveis e prontidão do Estado para levar a efeito projetos prioritários, e iii) estabilidade de preços, exceto para correções de alterações nas relações de troca. Em particular, uma vez que o comércio exterior pode ser útil para superar a maior parte dos gargalos internos, todas as operações em moeda estrangeira merecem cuidadoso tratamento pelo Estado. ${ }^{13}$ Nesse contexto, Kalecki fez a seguinte observação geral em sua discussão da economia israelense:

"Costuma-se dizer que todos os problemas poderiam ser solucionados de uma vez só abolindo-se as restrições à moeda estrangeira e os controles internos [...] As medidas recomendadas abaixo vão exatamente na direção oposta. Defende-se que deve ser feito o maior esforço possível para reduzir as importações e aumentar as exportações e, assim, depender o mínimo possível da importação de capital estrangeiro, mantendo ao mesmo tempo as mais estritas restrições cambiais possíveis. Essas medidas para melhorar o atual balanço de pagamentos exigirão um grau muito maior de supervisão e interferência governamentais do que foi feito até agora” (Kalecki, 1951 [1993]: 98-99).

Tomando essas premissas como ponto de partida, esboçaremos agora uma estratégia de crescimento, separando os aspectos de curto prazo dos de longo prazo.

\section{B) Crescimento econômico no curto prazo}

A existência de capacidade ociosa nas economias semi-industrializadas implica que o produto final poderia crescer significativamente no curto prazo. Bem, um primeiro requisito para isso é obviamente o crescimento da demanda efetiva. Em seu clássico artigo sobre políticas econômicas nas economias capitalistas avançadas, Kalecki (1944 [1990]) analisou três maneiras de se obter um crescimento suficiente da demanda (interna) de modo a assegurar o pleno emprego, tanto da força de trabalho como dos bens de capital. A saber:

“1. Através de gastos governamentais em investimento público [...] ou subsí-

casso na economia israelense" (Kalecki, 1951 [1993]: 103). A propósito, essa mesma ideia foi formulada de modo independente um pouco mais tarde por dois economistas latino-americanos, Schydlowsky (1967) e Diamand (1973).

${ }^{13}$ Ver também Sachs (1980). 
dios para consumo de massa [...] desde que esses gastos sejam financiados pelo [...] déficit orçamentário.

2. Estimulando os investimentos privados [...]

3. Redistribuindo renda das classes altas para as classes de baixa renda" (Kalecki, 1944 [1990]: 357).

Kalecki não era muito otimista sobre a possibilidade de basear o crescimento no estímulo aos investimentos privados. Por outro lado, era um forte partidário da redistribuição de renda por razões de justiça social, mas também pelo impacto favorável dessa redistribuição sobre a demanda e o emprego. Em muitos trabalhos ele analisou as vantagens do crescimento dos salários acima do crescimento da produtividade do trabalho (Kalecki, 1971 [1993]). Mas também observou que em alguns países menos desenvolvidos "[...] os funcionários administrativos e os trabalhadores não muito numerosos de grandes estabelecimentos [...] em países subdesenvolvidos estão em uma posição privilegiada, se comparados aos miseráveis da cidade e do campo [...]" (Kalecki, 1964 [1993]: 8).

A observação anterior parece sugerir que, na visão do autor, a redistribuição de renda através de um aumento generalizado dos salários não parece ser a melhor solução. ${ }^{14}$ Esses aumentos não beneficiam diretamente os mais pobres, que em muitos casos não são empregados de empresas formais, mas, ao contrário, são camponeses com um pouca ou nenhuma terra, trabalhadores autônomos ou empregados de setores informais; e, na verdade, poderiam mesmo trazer-lhes muito prejuízo, caso esses aumentos fossem transferidos para os preços dos produtos básicos. Um segundo antecedente sobre a melhor maneira de redistribuir renda está em seu trabalho acima citado sobre as três maneiras de alcançar o pleno emprego; Kalecki (1944 [1990]) enfatizou que os gastos públicos podem efetivamente ter um grande impacto redistributivo, pois podem ser canalizados, de modo mais preciso, para os grupos mais expostos.

Ao tratar de como financiar esses maiores gastos públicos, Kalecki (1937 [1990]) apoiou o déficit público, mas observou também que os déficits expandem os lucros juntamente com a demanda e, portanto, não contribuem para melhorar a distribuição da renda. Essa é uma limitação bastante grave em economias semiindustrializadas, onde a renda pode ser altamente concentrada.

Por essa razão Kalecki era, acima de tudo, um partidário de estimular a demanda efetiva por meio de gastos públicos financiados com impostos sobre os setores de alta renda, porque nesse caso os lucros não aumentam. Em um trabalho especificamente relacionado com as economias em desenvolvimento, Kalecki res-

\footnotetext{
${ }^{14}$ Queremos mencionar aqui a posição de Kalecki sobre a política da "frente popular" em países como a França e a Itália, discutida em um "workshop" polonês-italiano realizado em Ancona em 1965. O estudo de Kalecki nunca foi publicado, mas segundo I. Sachs (comunicação pessoal aos autores), que frequentou esse "workshop", ele acreditava que aumentos excessivos de salário podiam prejudicar a renda real do trabalhador em razão dos aumentos de preço.
} 
saltou duas outras vantagens dos gastos públicos financiados mediante impostos sobre os lucros.

"A redução do consumo dos capitalistas também será benéfica do ponto de vista do balanço de pagamentos, porque reduzirá a demanda por supérfluos importados" (Kalecki, 1954 [1993]: 41). Acrescentou que "Além de limitar o consumo dos capitalistas, o financiamento do investimento público mediante a cobrança de impostos apresenta ainda outra vantagem. Reduz a criação de disponibilidades [...]. Se [...] já houver há algum tempo uma espiral inflacionária, a grande quantidade de disponibilidades estimulará o entesouramento especulativo e ajudará assim a agravar o processo inflacionário primário".

Em seu estudo da economia israelense, Kalecki mencionou um outro problema, relacionado à acumulação de disponibilidades, a saber: "A acumulação de fundos líquidos não dispendidos, combinada com a incerteza da futura taxa oficial de câmbio, cria uma tendência natural para transferências ilegais para o exterior, que deprimem a libra israelense no mercado paralelo de moeda estrangeira. Esse mercado paralelo é uma experiência comum aos países com um balanço de pagamentos sob pressão, que necessita da manutenção de restrições cambiais” (Kalecki, 1951 [1993]: 97).

Em suma, podemos concluir que, na visão de Kalecki, a demanda efetiva deveria ser estimulada com base em uma elevação dos gastos públicos, financiada por impostos sobre os lucros. Além disso, o investimento público deveria ser planejado de tal modo que "sempre que faltassem os investimentos privados, o governo viesse em socorro, para que o investimento total pudesse alcançar o nível desejável” (Kalecki, 1996 [1993]: 16]. Simultaneamente, os gastos governamentais deveriam subsidiar os grupos de baixa renda.

No entanto, uma recuperação econômica rápida e sustentada, especialmente se apoiada em um elevado crescimento do emprego, acarreta uma grande demanda por alimentos, ao mesmo tempo em que a oferta interna de produtos agrícolas enfrenta obstáculos. Ele reconhecia que algumas medidas poderiam "expandir a produção agrícola no curto prazo. Essas medidas vão da reforma agrária e do crédito bancário barato aos camponeses até melhorias no método de cultivo, irrigação em pequena escala e fertilizantes baratos” (Kalecki, 1954 [1993]: 30). De qualquer modo, se o produto agrícola não crescer muito, os preços podem tender a crescer e a distribuição de renda poderá piorar. Se o país comercializar produtos agrícolas, a aceleração do crescimento será acompanhada de uma queda nas exportações ou de uma elevação nas importações de produtos agrícolas.

De modo geral, a recuperação econômica normalmente colocará em risco a balança comercial. A resposta do pensamento econômico convencional ao problema da deterioração da balança externa é neutralizar essa tendência, melhorando a competitividade através da desvalorização da taxa de câmbio. Kalecki, porém, recomendava soluções diferentes. Nas palavras dele: 
"Existe uma capacidade excedente considerável em Israel [...] nas indústrias leves, como de têxteis, roupas, sapatos, artigos de couro etc. Essa capacidade poderia ser mobilizada para as exportações, desde que fossem encontrados mercados para esses produtos no exterior [...] No entanto $[. .$.$] as mercadorias israelenses desse tipo são caras demais e exi-$ gem consideráveis prêmios de exportação. É essencial que esses prêmios sejam concedidos, mesmo se tiverem de chegar a uma porcentagem relativamente alta do valor agregado. Os prêmios de exportação devem, no entanto, ser mantidos no nível mais baixo possível, e outros incentivos devem também ser usados para expandir as exportações. A alocação de matérias-primas para a produção para o mercado interno deve ficar na dependência do desempenho da exportação das empresas, de forma a que elas fiquem estimuladas a exportar a preços menores do que os obtidos no mercado interno." (Kalecki, 1951 [1993]: 100).

\section{C) Investimento e crescimento de longo prazo}

Como mencionamos várias vezes, Kalecki achava que o problema crucial da economia subdesenvolvida era aumentar sua taxa de acumulação. Veremos agora como ele concebia essa questão em economias com abundante oferta de mão-de-obra. Ele discutia esse ponto referindo-se a uma economia socialista, mas sua visão também é válida para economias mistas. O modelo (Kalecki, 1963 [1993]) é muito simples: digamos que $\mathbf{i}$ seja a taxa (bruta) de investimento e $\mathbf{k}$ a relação técnica capital-produto (ou seja, o número de unidades de capital efetivamente em uso, necessário para produzir uma unidade de produto final). Digamos que $\mathbf{d}$ seja a taxa de depreciação e u a taxa extra de crescimento da produção anual que um país poderia obter se usasse mais e melhor os bens de capital existentes (expressamos i, u e $\mathrm{d}$ como proporções do PIB). Representamos por $r$ a taxa de crescimento da capacidade produtiva e especificamos um modelo de crescimento de longo prazo, como segue:

$$
r=\frac{i}{k}+u-d
$$

Essa fórmula simples mostra que, dados $\mathrm{k}$, $\mathrm{u}$ e d, a capacidade produtiva pode crescer somente se a parcela de investimento aumentar. Mas Kalecki enfatizou que k, u e d são parâmetros que um país pode modificar com medidas de política econômica. Assim, é possível aumentar u usando mais (e melhor) os bens de capital. Além disso, é possível reduzir d alongando a vida útil dos bens de capital. Finalmente, é possível reduzir a relação capital-produto k recorrendo a técnicas mais intensivas de mão-de-obra.

Do que foi dito acima, podemos deduzir que, na visão de Kalecki, canalizar adequadamente os investimentos ou realizá-los com tecnologias apropriadas pode ser tão importante quanto acelerar seu crescimento. Assim, ele recomendava dar 
prioridade a investimentos em capital necessários para fazer a maior e melhor utilização possível dos bens de capital herdados e mais antigos, a fim de alongar sua vida útil. ${ }^{15}$ Ao mesmo tempo, sempre que possível, ele propunha escolher técnicas produtivas que pudessem reduzir a relação capital-produto dos novos investimentos $(\mathbf{k})$.

Vamos considerar um processo de crescimento baseado no aumento do coeficiente $\mathrm{u}$, ou na redução dos coeficientes $\mathrm{k}$ e/ou d. Nesse caso, a taxa de investimento será menor em relação a uma outra estratégia onde os equipamentos mais antigos sejam descartados rapidamente, ou que se baseie em investimentos em tecnologias intensivas em capital. Consequentemente, no caso da primeira estratégia, o consumo ou sua taxa de crescimento não serão reduzidos a curto prazo, ou terão menor redução.

No entanto, uma estratégia como a sugerida de acordo com as ideias de Kalecki também tem custos. Em particular, se o crescimento econômico se basear em uma maior utilização dos equipamentos mais antigos, ou se for realizado com investimentos que exijam menos capital, então o nível (ou a taxa de crescimento) da produtividade do trabalho ficará reduzido e, assim, a demanda por mão-de-obra aumentará.

Consequentemente, o custo mais alto a pagar para alcançar o crescimento com uma estratégia baseada em uma maior utilização de capacidade ociosa aparece sob a forma de menores taxas de crescimento da produtividade do trabalho e, portanto, maiores necessidades de emprego. Mas esse é um custo que as economias semiindustrializadas podem se permitir, uma vez que nelas o desemprego de mão-deobra é generalizado. É somente depois, quando o excedente de mão-de-obra já tiver sido absorvido, que um país deveria mudar para uma estratégia que vise a aumentar a taxa de crescimento da produtividade do trabalho.

Poderíamos supor, então, que uma economia com capital e mão-de-obra ociosos pudesse crescer a taxas espetacularmente altas. No entanto, isso não acontece. Há limites para o crescimento de longo prazo, associados aos obstáculos que elas enfrentam quando tentam acelerar as taxas de expansão da agricultura, por um lado, e às dificuldades em garantir um elevado crescimento das exportações, por outro lado.

Kalecki enfatizava que o crescimento rápido está acompanhado de elevadas taxas de crescimento da demanda por alimentos. Ele também insistia nas barreiras técnicas e institucionais que entravam a expansão da produção agrícola nas economias capitalistas subdesenvolvidas. Ele achava que uma reforma agrária bem

\footnotetext{
15 “A modernização das velhas fábricas adquire uma importância especial. Essa modernização permite que seu equipamento produtivo e sua mão-de-obra sejam mais bem empregados, ao custo de despesas de investimento relativamente pequenas" (Kalecki, 1960 [1993]): 213). E também, referindo-se à economia israelense: "Investir em setores da indústria onde ainda exista capacidade ociosa, embora esse processo possa envolver considerável modernização, é um luxo a que a economia israelense não pode se permitir por enquanto. É exatamente esse o caso porque [...] não há escassez de mão-de-obra no momento" (Kalecki, 1951[1993]: 103).
} 
planejada e bem implementada era uma pré-condição para um crescimento de longo prazo elevado e estável. Apesar disso, acreditava também que o setor agrícola fosse claramente "determinado pela oferta". As observações a seguir referem-se a uma economia socialista, onde as barreiras institucionais foram superadas, mas onde, apesar disso, as barreiras estruturais limitam o crescimento:

"Uma importante distinção precisa ser feita entre dois tipos de indústrias [...] Chamaremos essas duas categorias de: indústrias determinadas pela oferta e indústrias determinadas pela demanda. Entendemos por indústrias determinadas pela oferta aquelas atividades que, por razões técnicas e organizacionais, têm um certo teto para a taxa de crescimento de longo prazo, de tal forma que mesmo um considerável aumento nos gastos de capital não fará o produto final crescer a uma taxa maior [...]

Os fatores tecnológicos e organizacionais dos quais dependem, por sua vez, os tetos da taxa de crescimento das indústrias determinadas pela oferta são de natureza muito variada. Os recursos naturais limitados são o exemplo mais simples e mais óbvio. O tempo necessário para a adaptação a novos progressos tecnológicos é outro exemplo. As dificuldades mais sérias na maneira de introduzir novas técnicas são provavelmente encontradas na agricultura, onde existe sempre um certo elemento de espontaneidade no desenvolvimento da produção" Kalecki, 1962 [1992]: 225).

Pode-se argumentar que o déficit na oferta interna de produtos agrícolas pode ser coberto com exportações de outros bens comercializáveis com alta elasticidade de oferta. ${ }^{16} \mathrm{O}$ problema, no entanto, é que pode ser difícil fazer as vendas externas crescerem a taxas elevadas e estáveis.

Realmente, é verdade que um país poderia tornar a produção rentável e competitiva graças à desvalorização da moeda ou a subsídios à produção interna. No entanto, a desvalorização da moeda agrava a distribuição de renda, e além de certos limites as vantagens dos subsídios se tornam progressivamente menores. Quando crescem as exigências de importação, e as exportações precisam acompanhar esse movimento, "Pode ser virtualmente impossível colocar as exportações nos mercados externos [...] Como resultado da pressão da oferta dos produtos em questão, seus preços médios podem cair de modo a tornar impossível atingir a receita em moeda estrangeira necessária para comprar as importações necessárias.

\footnotetext{
${ }^{16}$ Como já mostrado, em seu estudo para Israel, Kalecki recomendou diversas medidas de médio e longo prazo para equilibrar as contas externas em situações de crescimento rápido. Por exemplo, "É [...] claro que se pode alcançar uma considerável economia nas importações, investindo em indústrias de base. Em muitos casos, o custo do investimento é pequeno em relação à economia nas importações, chegando o valor agregado por ano a até três a quatro vezes o valor do maquinário necessário" (Kalecki, 1993 [1951]: 102).
} 
Ou [...] podem ser necessárias despesas muito elevadas de capital em relação aos efeitos em termos de câmbio [...]" (Kalecki, 1962 [1992]: 227).

Agora, para terminar nossa apresentação, devemos reconhecer que, de um certo ponto de vista, a estratégia baseada na visão de Kalecki - que favorece o investimento destinado a possibilitar um maior uso dos equipamentos mais antigos, ao mesmo tempo em que amplia seu tempo de vida, além de incorporar técnicas intensivas em mão-de-obra - acarreta uma desaceleração do progresso tecnológico. No entanto, com relação a isso, o argumento exposto pelo autor em seu estudo da economia israelense continua sendo válido:

“especialmente [quando] [...] não há escassez de mão-de-obra [...] a modernização [...] que visaria a poupar mão-de-obra não tem muito sentido do ponto de vista do interesse da economia como um todo. Podese argumentar que a modernização é necessária para reduzir custos e assim aumentar a capacidade de competir no exterior, o que aumentaria as exportações. Apesar disso, do ponto de vista da economia de moeda estrangeira, que é o fator mais escasso da economia israelense, é muito mais razoável pagar prêmios de exportação, por mais anormal que possa parecer esse subsídio a métodos obsoletos de produção" (Kalecki, 1951 [1993]: 103).

\section{OBSERVAÇÕES FINAIS}

Destacamos algumas das contribuições de Kalecki à teoria econômica do desenvolvimento, tanto do ponto de vista da compreensão de suas características particulares e mais relevantes e de seu modo de funcionamento, quanto da perspectiva do planejamento de seu desenvolvimento. Não pretendemos dizer que ele cobriu toda a matéria, mas ele estabeleceu as bases para futuros desenvolvimentos teóricos nessa área de nossa disciplina.

Em contraste com outros pioneiros da teoria econômica do desenvolvimento, Kalecki não deu destaque às forças internacionais que inibem o desenvolvimento, mas antes acentuou as instituições domésticas e os determinantes sociais e políticos. Em particular: as condições feudais e semifeudais da agricultura, o mercado reduzido resultante da concentração de renda e da monopolização generalizada da economia, e a falta de disposição dos empresários para realizar os investimentos necessários. Dessa forma, suas recomendações em termos de política econômica enfatizaram também os aspectos internos envolvidos.

Discutimos com certo detalhamento neste trabalho as medidas de política econômica que ele defendia e a estratégia de investimentos a longo prazo que podemos deduzir de seus escritos. Como a maioria dos economistas socialistas de sua época, Kalecki era bastante cético acerca das possibilidades de escapar do subde- 
senvolvimento sob o capitalismo. Apesar disso, olhando retrospectivamente, podemos perceber que, de fato, alguns países subdesenvolvidos, principalmente do Leste da Ásia, conseguiram superar o atraso econômico. Mas poderíamos também alegar que seu êxito foi possível porque a maior parte dessas economias empreendeu reformas agrárias radicais antes de embarcarem em um caminho de desenvolvimento rápido, porque todas elas tomaram medidas muito semelhantes às recomendadas por Kalecki, e porque em todas elas o Estado desempenhou um papel de destaque.

Este último aspecto não é desprezível. Em última instância, todas as medidas e toda a estratégia defendida pelo autor envolviam uma forte intervenção do Estado na economia. Isso não é surpresa, porque ele deu uma contribuição importante a uma das mais engenhosas e rigorosas propostas de estratégia macroeconômica sugeridas imediatamente após a Segunda Guerra Mundial para combater o desemprego no capitalismo. Assim, terminaremos nosso trabalho citando a afirmação final daquele estudo. Refere-se a uma economia desenvolvida, mas a ideia também é válida, e a nosso ver a fortiori, para uma economia subdesenvolvida.

"É óbvio que o pleno emprego exigirá um maior grau de controle governamental em assuntos econômicos do que foi a regra no passado. E é essa ampliação do poder do Estado que causa apreensão. Mas a alternativa aos controles que o pleno emprego acarreta não é um estado ideal de pleno emprego sem controles, mas desemprego e flutuações comerciais. As pessoas mais sofisticadas e economicamente mais afortunadas poderão argumentar que o desemprego é o preço a pagar para se ficar livre dos controles, e como tal pode ser tolerado. Mas esse é um falso argumento. Em primeiro lugar, controles setoriais eram generalizados no desemprego [...] Em segundo lugar, o argumento ignora a questão dos controles ocultos. Nesse sentido, o desemprego é o mais poderoso de todos os controles econômicos" (The Oxford University Institute of Statistics, 1947: 204-205).

\section{REFERÊNCIAS}

DELL, S. (1977) "Kalecki at the United Nations. 1946-1954" Oxford Bulletin of Economics and Statistics, 1977, (39): 31-45.

DIAMAND, M. (1973) Doctrinas económicas, desarrollo e independencia. Buenos Aires: Editorial Paidos.

FITZGERALD, E. V. K. (1990) "Kalecki on financing development: an approach to the macroeconomics of the semi-industrialized economy". Cambridge Journal of Economics, 1990, 14: 183-203.

FURTADO, C. (1960) "Industrialização e inflação". Economia Brasileira, v. 6 n. 3 e 4: 74-91.

KALECKI, M. (1937 [1990]) “A theory of commodity, income and capital taxation”. Em J. Osiatynsky, ed., Collected Works of Michal Kalecki, Vol. I Oxford: Oxford University Press, 1990.

KALECKI, M. (1938) [1993]) “Foreign trade and the national forces of production”, Em J. Osiatynsky, ed., Collected Works of Michal Kalecki, Vol. V Oxford: Oxford University Press, 1993.

KALECKI, M. (1944 [1990]) “Three ways to full employment”. Em Em J. Osiatynsky, ed., Collected Works of Michal Kalecki, Vol. I Oxford: Oxford University Press, 1990.

KALECKI, M. (1951 [1993]) "Report on the main current economic problems of Israel”, Em J. 
Osiatynsky, ed., Collected Works of Michal Kalecki, Vol. V Oxford: Oxford University Press, 1993.

KALECKI, M. (1954 [1993]) “The problem of financing economic development”. Em J. Osiatynsky, ed., Collected Works of Michal Kalecki, Vol. V Oxford: Oxford University Press, 1993.

KALECKI, M. (1960 [1993]) “Observations on labour productivity”. Em J. Osiatynsky, ed., Collected Works of Michal Kalecki, Vol. IV Oxford: Oxford University Press, 1993.

KALECKI, M. (1962 [1992]) "Outline of a method of constructing a perspective plan (Based on Polish experience)”. Em J. Osiatynsky, ed., Collected Works of Michal Kalecki, Vol. III Oxford: Oxford University Press, 1992.

KALECKI, M. (1963 [1993]) "Introduction to the theory of growth in a socialist economy". Em J. Osiatynsky, ed., Collected Works of Michal Kalecki, Vol. IV Oxford: Oxford University Press, 1993.

KALECKI, M. (1966 [1993]) "The difference between crucial economic problems of developed and underdeveloped non-socialist economies”. Em J. Osiatynsky, ed., Collected Works of Michal Kalecki, Vol. V Oxford: Oxford University Press, 1993.

KALECKI, M. (1971 [1991]) “Class struggle and the distribution of national income”. Em J. Osiatynsky, ed., Collected Works of Michal Kalecki, Vol. II. Oxford: Oxford University Press, 1991.

MANOILESCU, M. (1931) The Theory of Protection and International Trade. Londres: P.S.King \& Son.

NOYOLA, J. (1956) "El desarrollo económico y la inflación en México y otros países latinoamericanos." Investigación Económica. XVI:4; 603-48. Uma nova versão aparece em "Desequilibrio externo e inflación. Investigación Económica", ed. UNAM, 1987.

NURKSE, R. (1953) Problems of Capital Formation in Underdeveloped Countries. New York: Oxford University Press.

PREBISCH, R. (1951 [1982]), “Problemas teóricos y prácticos del crecimiento económico.” In Gurrieri, Adolfo, ed. (1982) La Obra de Prebisch en la CEPAL. México: Fondo de Cultura Económica.

ROSENSTEIN-RODAN, P. (1943), "Problems of industrialization of Eastern and South-Eastern Europe,” The Economic Journal, v. 53 (210): 202-211.

SACHS, I. (1977) "Kalecki and development planning" Oxford Bulletin of Economics and Statistics, 1977, (39): 47-56.

SACHS, I. (1980) Studies in political economy of development. Oxford: Pergamon Press.

SCHYDLOWSKY, D. (1967) "From import substitution to export promotion for semi-grown up industries: a policy proposal”. Journal of Development Studies, III, 4, July.

STEINDL, J. (1942 [1946]) “The impact of the war on India”. Em A. J. Brown, ed. Studies in War Economics. Oxford: Oxford University Press.

SUNKEL, O. (1960) "Inflation in Chile; an unorthodox approach". International Economic Papers n. 10: 107-131.

The Oxford University of Economics and Statistics (1944) The economics of full employment. Oxford: Basil Blackwell. 